Boise State University

ScholarWorks

Geosciences Faculty Publications and

Presentations

Department of Geosciences

$11-2014$

\title{
Introduction to an Open Community Infrasound Dataset from the Actively Erupting Sakurajima Volcano, Japan
}

David Fee

University of Alaska Fairbanks

Akihiko Yokoo

Kyoto University

Jeffrey B. Johnson

Boise State University 


\section{Introduction to an Open Community Infrasound Dataset from the Actively Erupting Sakurajima Volcano, Japan}

\section{by David Fee, Akihiko Yokoo, and Jeffrey B. Johnson}

Online Material: Movie of time-synced visual and infrasound data of two explosions at Sakurajima Volcano, Japan.

\section{INTRODUCTION}

Active volcanoes are significant sources of seismic and acoustic radiation. Extensive work has shown that infrasound is an effective tool to study and monitor active volcanoes. Infrasound is now a regular tool utilized by volcano observatories to aid in volcano monitoring and hazard mitigation. Infrasound-based studies are able to provide important information on eruption dynamics and to develop quantitative models of volcanic eruptions. In addition, volcanoes provide excellent acoustic sources for atmospheric propagation studies and can be used to infer atmospheric dynamics and structure (see Johnson and Ripepe, 2011; Fee and Matoza, 2013 for recent reviews on volcano infrasound). The number of infrasound sensors and studies is also increasing rapidly, including those deployed as part of the USArray Transportable (seismic) Array. Lastly, seismic and acoustic records provide complementary information on both volcanic and nonvolcanic sources and elastic wave propagation in the Earth and atmosphere (Arrowsmith et al., 2010).

Although the number of volcano infrasound stations and research studies has increased substantially in recent years, many questions remain unresolved. For example, current work is focused on the spatial and temporal variability of the atmosphere and how it affects infrasound propagation at distances of a few to thousands of kilometers (Johnson et al., 2012; Fee and Matoza, 2013; Lacanna et al., 2014). Other studies are beginning to assess the effects of complex topography and volcanic crater morphology on infrasound signals recorded at both local and regional distances (e.g., Matoza, Garces, et al., 2009; Kim and Lees, 2011; Lacanna and Ripepe, 2012). To date, most volcano infrasound studies assume linear sound propagation from the source, yet this assumption may not be valid for all volcanic explosions and has not been tested extensively (e.g., Yokoo and Ishihara, 2007). Quantitative volcano acoustic source models are poorly constrained in most cases, in part from propagation uncertainties and network density limitations (e.g., Johnson et al., 2008; Kim et al., 2012). Seismo- acoustic and acoustic-seismic coupling may be prevalent in volcanic regions (e.g., Matoza, Garces, et al., 2009; Ichihara et al., 2012; Matoza and Fee, 2014), yet the nature of the coupling has not been fully explored. These and other poorly resolved questions remain in part because of the logistical challenges in deploying dense sensor networks near volcanoes that are frequently active. Volcanoes are inherently difficult places to work due to inhospitable surroundings, challenging logistics, and dynamic nature of volcanic activity.

A unique opportunity arose in July 2013 that permitted an unprecedented volcano infrasound dataset to be collected at Sakurajima, Japan. This dataset, together with other infrasound data recently collected from Sakurajima, will be featured this Focus Section. In July 2013, the International Association of Volcanology and Chemistry of the Earth's Interior (IAVCEI) Scientific Assembly convened in Kagoshima, Japan, the city adjacent to Sakurajima, an active volcano renowned for its frequent explosions that generate very intense infrasound. Sakurajima Volcano, which is easily accessible by paved road encircling the edifice, is well monitored with a multiparameter network operated by the Sakurajima Volcano Observatory (SVO; now the Sakurajima Volcano Research Center). Because this conference attracted more than 1000 volcanologists from around the world, the IAVCEI Volcano Acoustics Commission organized a postconference workshop focused on all aspects of volcano acoustics. The two-day workshop, attended by $\sim 50$ individuals, provided a framework for discussion on current topics and outstanding issues in volcano acoustics. The participation of early career scientists was emphasized, as was outreach to the local communities. In addition, through collaboration with SVO, a dense network of volcano acoustic sensors was deployed directly prior to the workshop for 8 days in July 2013 (see Sakurajima Volcano section). The short-term deployment included multiple sensor types with various deployment topologies, including both arrays and a larger network, with some sensors collocated for comparison.

During this period, diverse infrasound was recorded from Sakurajima, including over 34 high-amplitude explosions. The dataset was subsequently presented at the workshop, distributed to the participants, and is now available for public down- 
load from the Incorporated Research Institutions for Seismology Data Management Center (IRIS-DMC). The ease of access, high level of volcanic activity, local network capabilities, and extensive collaboration permitted a high-quality volcano acoustic dataset to be collected. Its open distribution and provision to the scientific community has precedent within the seismic community, where waveform data is often freely shared. It is our hope that this high-quality dataset will be openly used for research and education and will encourage open distribution of volcano acoustic data and innovation in the future.

This Focus Section contains seven articles covering a wide range of topics, broadly linked by the theme of Sakurajima infrasound; five of the papers make use of the open-source dataset whereas one other uses complementary data. This introductory manuscript provides an overview to the data collected and points out some general observations relevant to the broader seismo-acoustic and volcanology communities. Johnson and Miller (2014) apply waveform modeling to estimate volume of erupted material associated with the Sakurajima explosions. Kim and Lees (2014) use novel graphical processing unit-based finite difference time domain processing to investigate 3D infrasound propagation and source localization. McKee et al. (2014) test the network semblance method on acoustic source localization at Sakurajima and use it to help characterize volcanic activity. Matoza et al. (2014) focus on the variety of explosions signals at Sakurajima and other volcanoes that do not fit within previous volcanic explosion models. Yokoo et al. (2014) use array processing techniques to determine multiple-infrasonic source locations and examine the role of near-vent topography. We believe the dataset gathered and the high-quality manuscripts in this Focus Section will serve as a benchmark for future infrasound studies and will lead to significant advances in the field.

\section{SAKURAJIMA VOLCANO}

Sakurajima Volcano $\left(31.59^{\circ} \mathrm{N}, 130.66^{\circ} \mathrm{E}\right.$, elevation $\left.\sim 1117 \mathrm{~m}\right)$ is an active volcano in southern Kyushu, Japan (Fig. 1), just $\sim 8 \mathrm{~km}$ east of Kagoshima City (population $~ 606,000$ ). Nearly 5000 local residents live on the flanks of the volcano, which is practically an isolated island connected to the mainland in the east by a narrow isthmus. Sakurajima is a postcaldera and andesitic-dacitic volcano, constructed 26,000 years ago (Kobayashi et al., 2013). It occupies a position near the southern edge of the Aira Caldera, which retains relatively youthful caldera morphology. Chemical composition of the recent erupted materials is $59 \% \mathrm{SiO}_{2}$ (Matsumoto et al., 2013).

The last large eruptions at Sakurajima occurred in 1914 and 1946, when extensive lava flows $\left(1.3\right.$ and $0.8 \mathrm{~km}^{3}$, respectively) effused from the flank craters. Persistent explosive activity has been focused at the summit crater (Minamidake) since $\sim 1955$ in the form of ash-rich, vulcanian-style eruptions that typically have strong acoustic waves (Ishihara, 1985). In 2003, activity declined at the summit crater and in 2006 shifted to the Showa crater on the southeast side of the volcano (Fig. 1) and continues there today. Showa crater lies on the flank of the main edifice and is surrounded by significant topography. Typical eruptions are archetypically vulcanian and result in small $(<3 \mathrm{~km}$ above sea level [km.a.s.l.]) ash plumes and large (meter-sized) blocks ejected to distances of $1-3 \mathrm{~km}$. Since 2009, these eruptions occur frequently and number $\sim 1000$ per year. Rare but hazardous pyroclastic flows also occasionally threaten local communities (Yokoo et al., 2013).

Sakurajima Volcano is monitored using a multiparameter network established and run by the SVO of Kyoto University $(\mathrm{KU})$. This network consists of 10 seismic sensors, 4 infrasound sensors, 1 thermal and 2 video cameras, 8 borehole tilt meters, and 2 sets of water-tube tiltmeters and strain meters inside underground tunnels (Iguchi et al., 2013), making it one of the most heavily instrumented and best monitored volcanoes in the world. A cyclic inflation-deflation deformation cycle associated with explosions has been identified and assists with short-term precursory forecasting (Iguchi et al., 2008; Yokoo, et al., 2013). Regular measurements of $\mathrm{SO}_{2}$ and ash are also taken (Shimano et al., 2013).

In addition to continuous monitoring, numerous seismoacoustic studies have been undertaken at Sakurajima. Kamo et al. (1994) used local seismometers and pressure sensors to identify explosions at Sakurajima. Building on the work of Tahira (1982), they also measured long-range infrasound signals from Sakurajima and were amongst the first researchers to propose an acoustic monitoring system for volcanic eruptions. An early study by Iguchi and Ishihara (1990) characterized the very high-intensity pressure signals associated with Sakurajima's vulcanian eruptions and contrasted them with explosions from Suwanosejima Volcano. Seismic and geodetic studies at Sakurajima have focused on the source processes leading up to and during explosive eruptions. Inflation and deflation cycles for each eruption, corresponding to magma supply and release, are identified in both the tilt and strain records (Ishihara, 1990). Moment tensor analysis of explosion earthquakes (Uhira and Takeo, 1994; Tameguri et al., 2002) revealed the occurrence of a deep implosion ( $\sim 2 \mathrm{~km}$ depth) for vulcanian eruptions that corresponds to upward movement of the magma or gas. Expansion-and-contraction at shallow depths $(\sim 0.5 \mathrm{~km})$ immediately after the deep implosion is identified by the seismic moment as well (Tameguri et al., 2002). This shallow process manifests as a "strain-step" (Ishihara, 1990) due to the release of pressure, which ultimately relates to the radiation of a high-amplitude infrasound signal at the start of the explosion.

Other important infrasound-focused studies have followed, including several studies that incorporated integrated multiparameter geophysical data. Garces et al. (1999) found an increase and change in small acoustic events leading up to a larger vulcanian explosion. This dataset was further analyzed by Morrissey et al. (2008) using a joint seismo-acoustic approach. Yokoo et al. (2009) used high-frame rate video and infrasound sensors to identify a precursory acoustic wave associated with the swelling of the viscous lava plug just prior to an explosion. This precursory wave was followed by a shock wave associated with the onset of the main explosion. Yokoo et al. (2013) expanded on previous work by others (e.g., Iguchi et al., 


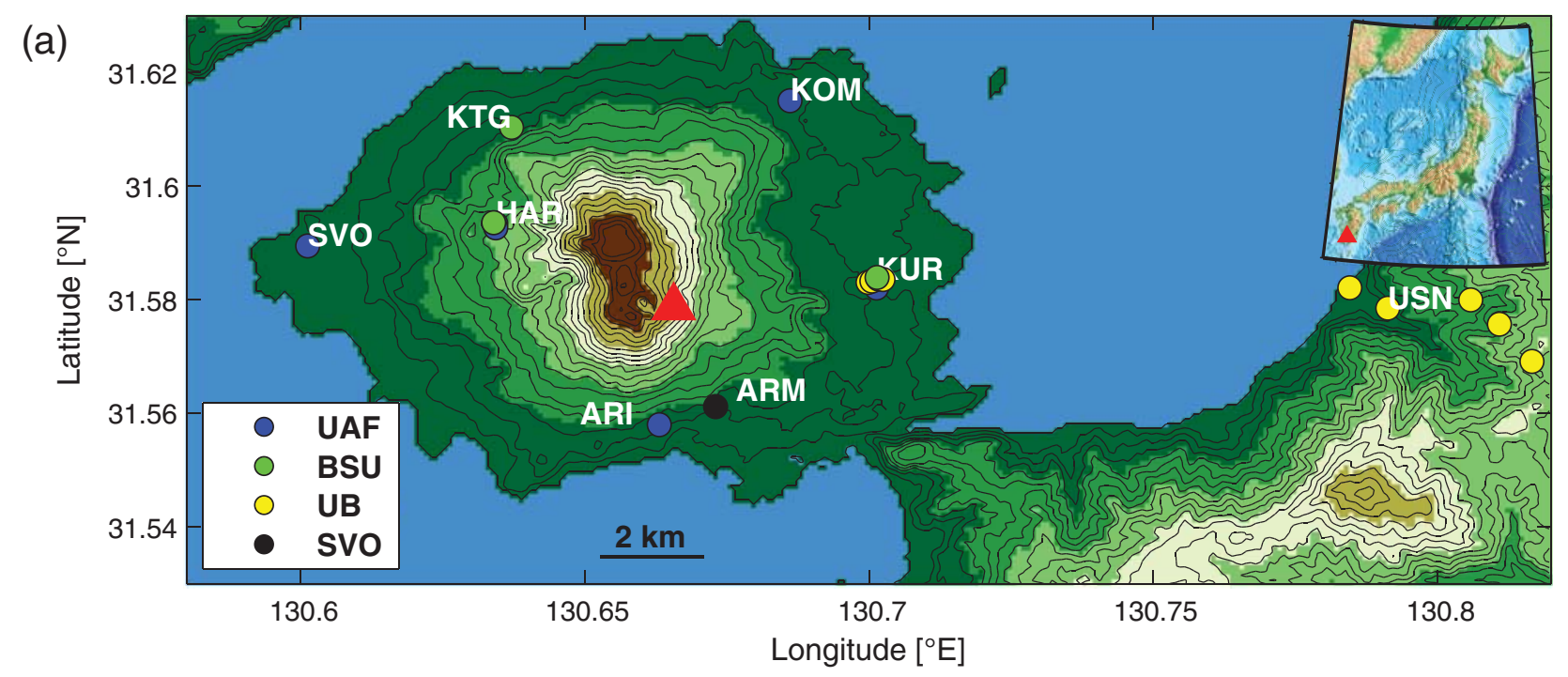

(b)

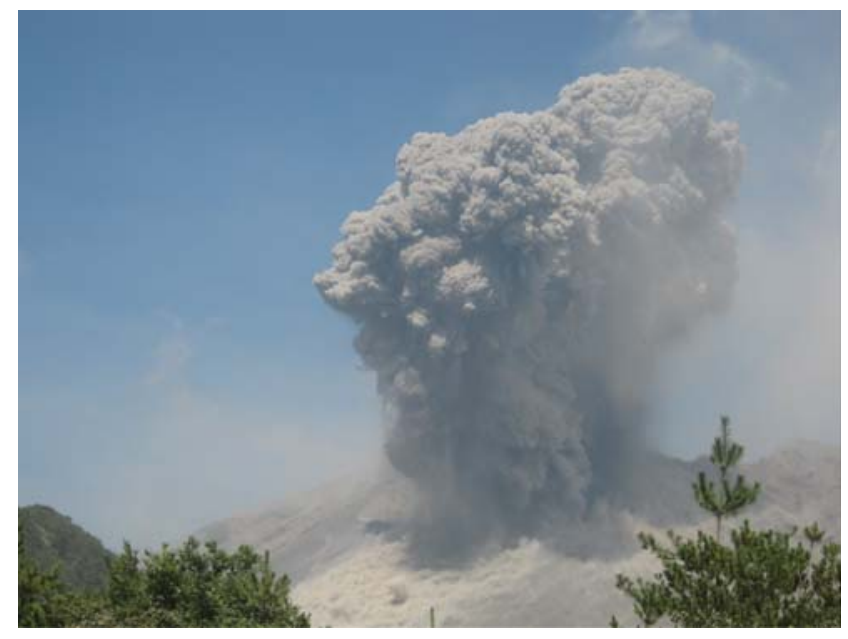

(c)

A Figure 1. (a) Map of Sakurajima Volcano and stations deployed in July 2013. Red triangle indicates the active vent within Showa crater. Various sensor deployments are denoted as follows: University of Alaska Fairbanks (UAF), Boise State University (BSU), University of Bristol (UB), and Sakurajima Volcano Observatory (SVO). (b) Image from station KUR of a typical vulcanian explosion on 21 July 0056 UTC. (c) Ash plume rising above Sakurajima as viewed from near Kagoshima ( 8 km west of the vent).

2008) and utilized a multiparameter dataset to model the processes leading up to vulcanian explosions at Sakurajima.

\section{DATA COLLECTION}

Multiple infrasound sensors were deployed around Sakurajima in July 2013 by a collaborative team from the University of Alaska Fairbanks (UAF), Boise State University (BSU), and KU. Figure 1 shows the location of all acoustic sensors deployed on Sakurajima during mid-July 2014, and Table 1 provides the sensor locations and slant distance and azimuth to the vent.

UAF deployed five stand-alone digital sensors in a network-style configuration around the volcano (HAR, ARI, SVO, KUR, and KOM). Three sites had National Center for Physical Acoustics (NCPA) digital infrasound sensors with piezo-ceramic sensing elements with 24-bit digitizer and
Global Positioning System timing. These low-noise sensors have a flat frequency response between $\sim 0.02$ and $250 \mathrm{~Hz}$ and pressure range of $\pm 1190 \mathrm{~Pa}$. The other two UAF sites had Hyperion IFS-5201 digital infrasound sensors with a similar design as the NCPA versions, with flat frequency response between $\sim 0.02$ and $250 \mathrm{~Hz}$ and pressure range of $\pm 1000 \mathrm{~Pa}$. All five sites were sampled at $500 \mathrm{~Hz}$ and recorded between $\sim 18$ and 27 July 2013. BSU deployed two small aperture arrays of six sensors at various times at site KUR, KTG, and HAR (Fig. 1). The array site at KUR remained for the duration of the experiment. KTG recorded between 18 July 0700 and 19 July 0300 UTC and was moved to HAR between 19 July 0500 and 22 July 0200 UTC. Six elements were installed at KUR on 18 July, and six more were added (from HAR) on 22 July. BSU sites consisted of infrasonic microphones packaged at BSU's infrasound lab, which incorporate AllSensors MEMs pressure 
Table 1

Station Locations and Information

\begin{tabular}{cccccccc|}
\hline $\begin{array}{c}\text { Station } \\
\text { Name }\end{array}$ & Latitude $\left({ }^{\circ} \mathbf{N}\right)$ & Longitude $\left({ }^{\circ} \mathrm{E}\right)$ & Elevation $(\mathbf{m})$ & $\begin{array}{c}\text { Distance to } \\
\text { Vent }(\mathbf{m})\end{array}$ & $\begin{array}{c}\text { Azimuth to } \\
\text { Vent }\left({ }^{\circ} \mathbf{N}\right)\end{array}$ & $\begin{array}{c}\text { Sensor } \\
\text { Type }\end{array}$ & $\begin{array}{c}\text { Deployment } \\
\text { Group }\end{array}$ \\
\hline KUR & 31.58355 & 130.70130 & 61 & 3487 & 261 & HYP & UAF \\
ARI & 31.55802 & 130.66314 & 100 & 2400 & 6 & NCPA & UAF \\
KOM & 31.61504 & 130.68611 & 133 & 4525 & 206 & HYP & UAF \\
HAR & 31.59340 & 130.63428 & 410 & 3408 & 119 & HYP & UAF \\
SVO & 31.58946 & 130.60114 & 39 & 6263 & 101 & NCPA & UAF \\
KURA & 31.58374 & 130.70139 & 75 & 3487 & 261 & MEMS & BSU \\
KTGA & 31.61034 & 130.63709 & 120 & 4486 & 142 & MEMS & BSU \\
HARA & 31.59355 & 130.63395 & 390 & 3408 & 119 & MEMS & BSU \\
\hline
\end{tabular}

Distance to vent is slant distance. Stations ending in "A" denote an array. Sensor types are Hyperion IFS-5201, NCPA digital infrasound sensors, and AllSensors MEMs pressure transducers.

transducers with ranges up to $\pm 1250 \mathrm{~Pa}$ and flat frequency response above $\sim 0.04 \mathrm{~Hz}$. Operation and calibration of this type of microphone is discussed in Marcillo et al. (2012). BSU pressure data was digitized at $200 \mathrm{~Hz}$ using 24-bit Omnirecs DATA-CUBE recorders.

The aforementioned campaign deployments supplemented the existing SVO network, as well as two research arrays (KUR and USN) deployed concurrently by the University of Bristol (UB) and KU on a separate project (Fig. 1). The UB-KUR array consisted of three Hyperion IFS-3000 sensors and one Chaparral $25 \mathrm{Vx}$ and was arranged as a linear array over $\sim 250 \mathrm{~m}$ about $3 \mathrm{~km}$ from Showa crater. The UB-USN array had five infrasound sensors (Datamark SI102) deployed roughly linear extending east of the active vent between $\sim 11.5$ and $14.5 \mathrm{~km}$. The UB sensors were deployed primarily for a separate research project and will be discussed in future work. The SVO network has infrasound sensors at sites ARM, HAR, KUR, and SVO (Fig. 1). They are ACO 7144 at ARM and HAR and Datamark SI100 at KUR and SVO. All data from the sensors are logged by Datamark LS7000 or LS7000XT. Array data at KUR from a December 2011 campaign using

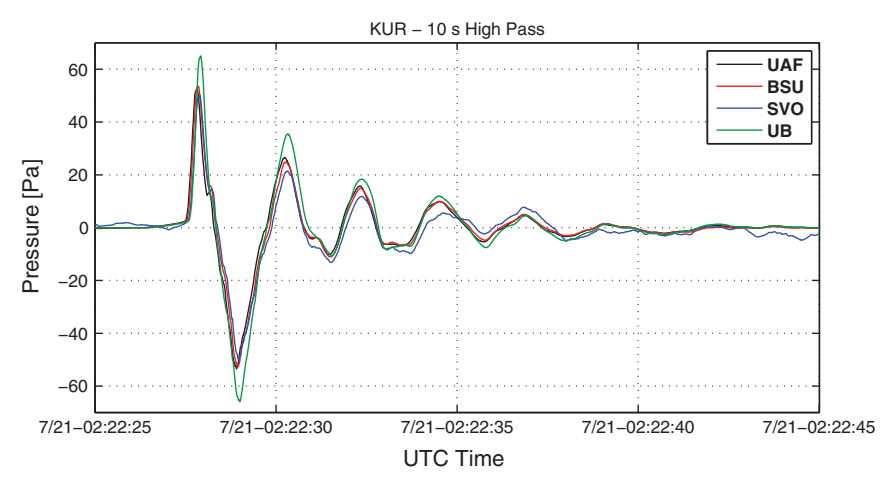

- Figure 2. Sensor comparison at station KUR. Waveforms for each station are high-pass filtered above $10 \mathrm{~s}$. Timing and amplitude agree very well between the sensors, with the amplitude of the UB sensor being the exception. nine sets of sensor and logger (Datamark SI102 and Datamark LS8800) are utilized in Yokoo et al. (2014).

Data were gathered and quality controlled before being distributed to the workshop participants. Collocated diverse sensor types were quantitatively compared to assess relative instrument responses. Figure 2, for example, shows waveforms for a typical explosion recorded on multiple sensors at site KUR. This site is unique in that it has four nearly collocated infrasound sensors. Displayed data from the BSU, UAF, UB, and SVO deployments are high-pass filtered above $10 s$ with a twopole, causal, Butterworth filter to ensure similar response characteristics. In general, the waveform shape, amplitude, and timing are consistent between the four sensors. The exception is the Bristol recording, which appears to have amplitudes 25\% higher, suggesting that the calibration value of the sensor or digitizing system may need to be re-evaluated. UAF and BSU data were assembled and distributed to workshop participants via FTP and are now available via IRIS-DMC. The data from the UAF and BSU deployments now serve as open resource to the seismo-acoustic community for use in education, training, and research.

\section{DATA OVERVIEW AND DISCUSSION}

The diverse infrasound data collected from Sakurajima in July 2013 provide insight into the volcano's activity, eruption physics, and wave propagation in the presence of complex topography. Sakurajima infrasound is notable for the regular high-amplitude, short-duration explosions, which are often followed by lower level, sustained infrasonic tremor or jetting. Figure 3 shows a pseudohelicorder plot of $24 \mathrm{~h}$ of infrasound data from Sakurajima on 21 July with each line displaying $60 \mathrm{~min}$ of data. Time periods of infrasound production from Sakurajima are determined using cross-correlation analysis on the BSU KUR array. Cross correlation on array station pairs is performed in $10 \mathrm{~s}$ overlapping windows, which have been time shifted to account for propagation time from source to receiver. Data are band-pass filtered between 1 and $20 \mathrm{~Hz}$ to capture the 


\begin{tabular}{|l|l|l|l|l|l|}
\hline 0.5 & 0.6 & 0.7 & 0.8 & 0.9 & 1 \\
\hline
\end{tabular}

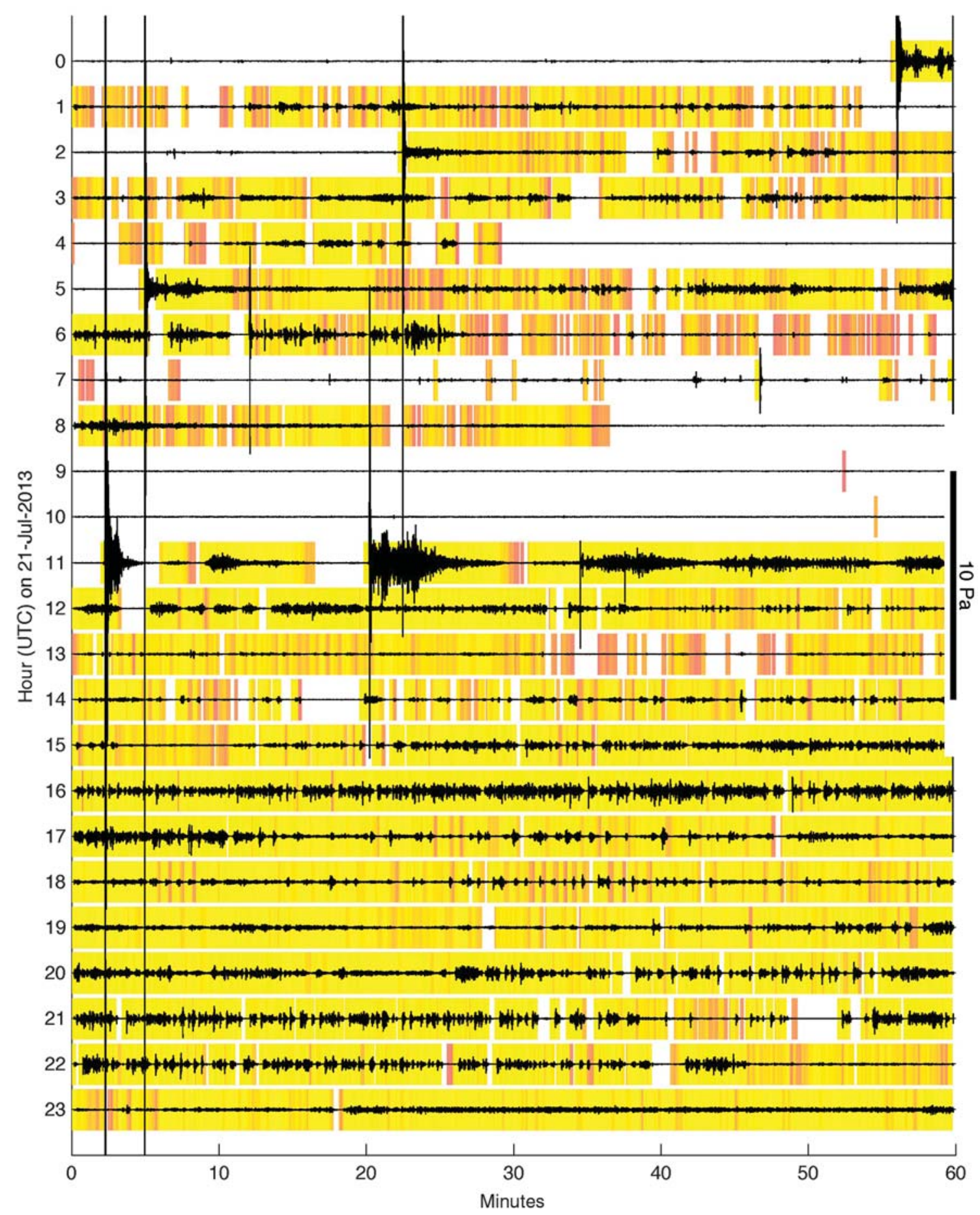

A Figure 3. Pseudohelicorder plot for 21 July. Array processing is used to detect coherent infrasound originating from the direction of Showa crater. Four channels (Numbers 1, 2, 4, and 6) of the KURA array are used to identify consistent and well-correlated (>0.5) signals over $10 \mathrm{~s}$ overlapping windows. Consistency criterion is used to assess that correlation lag times are robust. Array detections provide a means to identify volcano infrasound even for small amplitude tremor or pulses that would be difficult to identify through visual inspection alone. Data are band-pass filtered between 1 and $20 \mathrm{~Hz}$. 
majority of the acoustic energy from the volcano and to reduce low-frequency noise. Periods of high cross-correlation values indicate the prevalence of both explosions and tremor. Large explosions are apparent in Figure 3 at 0056, 0222, 0505, 0800, 1102 , and 1120 UTC, whereas hours 1200-2300 have nearcontinuous infrasonic tremor. Figure $1 \mathrm{~b}, \mathrm{c}$ displays images of typical activity at Sakurajima: an energetic explosion and lowlevel ash plume during a tremor episode.

We also apply a short-term average/long-term average (STA/LTA)-based method to identify large explosions during the eight-day deployment. Data from station ARI are first filtered between 0.3 and $10 \mathrm{~Hz}$. STA and LTA lengths of 2 and $10 \mathrm{~s}$, respectively, and an STA/LTA ratio of 20 are chosen. A minimum peak pressure threshold of $10 \mathrm{~Pa}$ at ARI is used to cull out low signal-to-noise ratio and low-amplitude events. Using these methods, we detect 34 explosions during the deployment, with peak pressures ranging from 13 to $449 \mathrm{~Pa}$ at ARI, which is located $2.4 \mathrm{~km}$ from Showa crater. These explosions are displayed in Figure 4 and listed in Table 2.

The infrasonic signature of explosions at Sakurajima shares some similar characteristics but also show some variability. The large explosions are usually preceded by an absence of infrasound shown as white background color in Figure 3 (e.g., hours 21 July 0815-1100 UTC), suggesting a closed vent prior to explosive eruptions. Time duration of vent sealing varies significantly during the experiment, from minutes to hours. Similar precursory vent sealing was observed at Karymsky Volcano, Kamchatka for explosions of similar magnitude and composition (Lopez et al., 2013).

Figure 5a shows a typical explosion waveform recorded at station ARI. After a period of vent sealing, the explosion begins with a slow rise in pressure lasting $\sim 0.75 \mathrm{~s}$ (Fig. $5 \mathrm{~b}$ ), which has been previously attributed to the swelling of the viscous lava plug (Yokoo, et al., 2009). A strong compression occurs next and indicates the explosive disruption of the plug. A rarefaction then follows and is often of lesser amplitude and longer period, reminiscent of a blast wave from a chemical explosion. The next few seconds often have complex waveforms, but many are characterized by a damped oscillation that often transitions into lower intensity tremor and/or jetting that can last for minutes to hours. The explosions typically have peak spectral periods of $\sim 1-3$ s. (E) Supplementary video 1 displays time lapse imagery and infrasound data for two explosions on 19 July. Each explosion is preceded by a period of vent sealing and consists of a short-duration burst of acoustic energy coincident with ballistics and an ashy plume. These observations from 2013 are consistent with recent acoustic observations made at Sakurajima in 2009 (e.g., Yokoo et al., 2013).

Explosions at Sakurajima occasionally produce very highamplitude infrasound. The waveform in Figure 5 is an example of one of the highest amplitude explosions recorded during the study at 21 July $\sim 1102$ UTC at station ARI. This eruption produced an ash-rich plume to $3.7 \mathrm{~km} . a . s . l .$, ejected bombs, and produced visible lightning in the plume. The peak pressure at ARI is $426 \mathrm{~Pa}$ at $2.3 \mathrm{~km}$, corresponding to a reduced pressure of $980 \mathrm{~Pa}$ at $1 \mathrm{~km}$. Reduced pressure is calculated assuming a $1 / r$ pressure decrease (Johnson and Ripepe, 2011). This value is very high compared to many previously published explosion signals (Johnson and Ripepe, 2011) but is not anomalous for Sakurajima where exceptionally high-amplitude infrasound has been routinely recorded (e.g., Iguchi and Ishihara, 1990). For comparison, impulsive signals from the 2006 explosive eruption of Augustine Volcano, Alaska, produced reduced pressures up to $336 \mathrm{~Pa}$, but this eruption was considerably larger producing much higher plumes up to $11 \mathrm{~km}$.a.s.l. (Petersen et al., 2006).

Most explosive events during the deployment could be classified as vulcanian, the typical style of activity for Sakurajima. The explosions produced ash-rich plumes and extensive ballistics, with volcanic bombs often ejected hundreds of meters from the active vent. Lightning within the plume also accompanied many of the events. No pyroclastic flows were observed. Plume heights associated with the explosions varied between 1.8 and $6.1 \mathrm{~km}$.a.s.l. during the deployment and were sourced from the Showa crater at $\sim 750$ m.a.s.l. Figure 6 shows plume heights versus the peak pressure at station ARI for each explosion. All plume heights used here were determined by the Tokyo Volcanic Ash Advisory Centre (VAAC). There does not seem to be a robust correlation between the two parameters, as has been suggested for some other volcanoes (e.g., McNutt et al., 2013). The paper by Johnson and Miller (2014) examines the relatively poor scaling of infrasound amplitude and plume height.

Most commonly, the peak pressure typically occurs at the very beginning of the explosion (Figs. 3-5) and represents initial disruption of the viscous magma plug and onset of magma fragmentation or release of a gas pocket (Yokoo et al., 2013). Visual observations confirm many of the plumes are driven by extended processes occurring for minutes to hours after the initial burst. These periods are associated with low frequency $(<3 \mathrm{~Hz})$ tremor or jetting that often lasts for minutes after the beginning of an explosion (Fig. 3), along with audible rumbling and jetting. We also note the first few seconds of the eruption occasionally show complex and variable pressure-time histories (Fig. 4), suggesting that fragmentation and/or explosive gas release is not always instantaneous or sourced from a uniform location. In addition to the common bipolar compression/rarefaction pulse at the onset of the explosion, numerous explosions begin with multiple lower amplitude compressions. This may result from the slow explosion of the magma plug and is addressed by Matoza et al. (2014). Note the peak amplitude for these slow explosions are generally lower than the bipolar explosions, and some have a reduced rarefaction or none at all. Other volcanoes with similar composition and style of activity (e.g., Karymsky Volcano, Kamchatka and Augustine Volcano, Alaska) occasionally show this behavior as well (Fee and Matoza, 2013). In addition to variable explosion onsets, the subsequent coda also shows variability between explosions, again suggesting a complex pressure release time history during the first few to tens of seconds of the explosion.

Sakurajima explosion waveforms exhibit significant variability across the network for a given eruptive event. Figure 7 displays the raw waveforms for the five UAF network stations for a high-amplitude explosion, with each waveform amplitude 

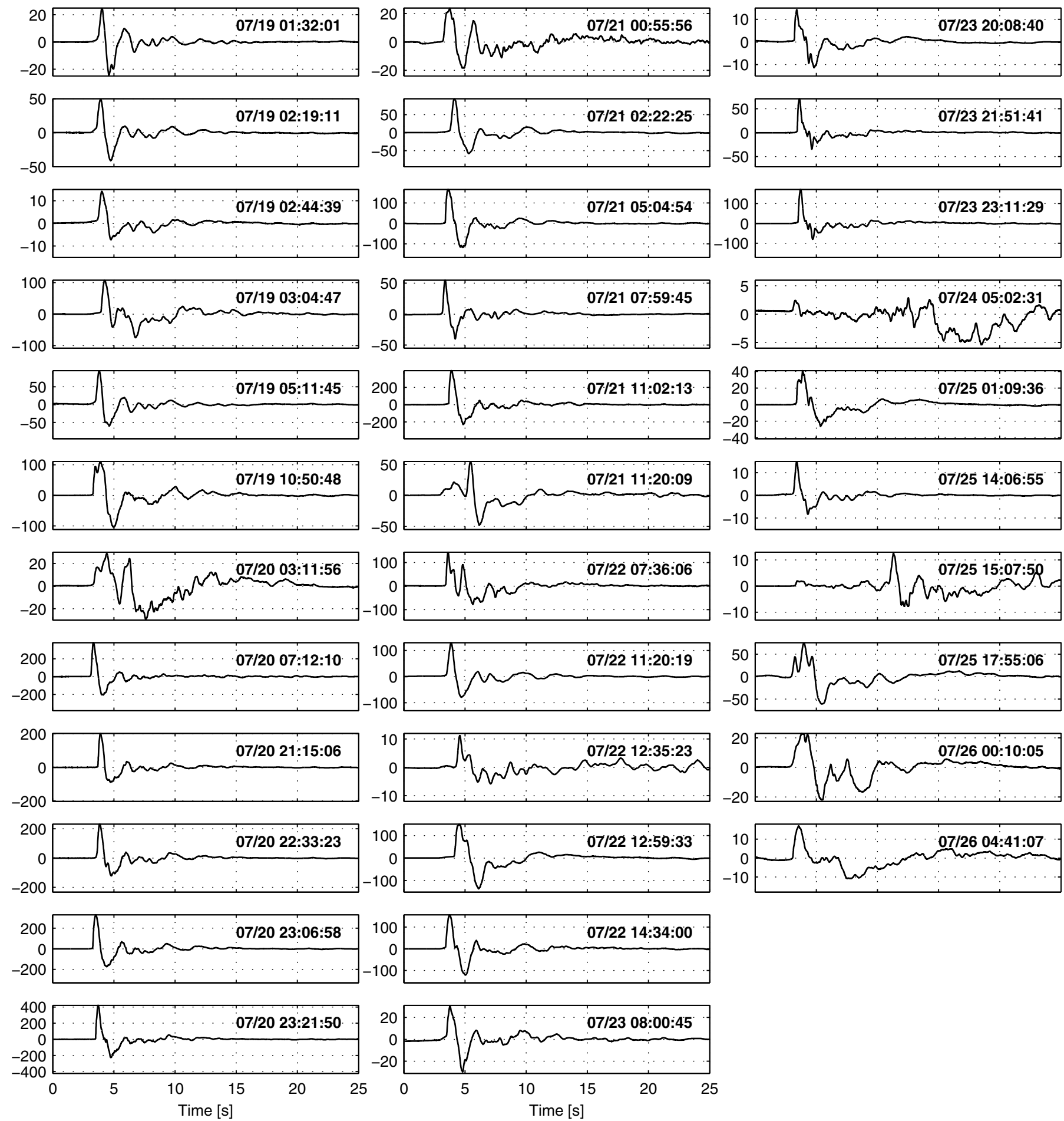

$\Delta$ Figure 4. Waveforms for the 34 detected high-amplitude explosions during the deployment. Although some similarities exist among explosions, significant variability is also present. See Data Overview and Discussion section for details on detection method. Waveforms are high-pass filtered above $0.05 \mathrm{~Hz}$ to reduce low-frequency noise.

corrected to a reduced distance of $1 \mathrm{~km}$ assuming $1 / r$ (spherical) spreading. An isotropic source with radiation into a homogeneous and stationary (no wind) atmosphere and negligible topography should produce the same amplitudes and waveforms across the network; however, it is clear in Figure 7 that significant waveform distortion is occurring. Reduced pressures vary greatly, from $\sim 500 \mathrm{~Pa}$ at $\mathrm{HAR}$ to $\sim 1400 \mathrm{~Pa}$ at KUR. Waveform shape also varies significantly, with stations HAR and SVO having a diminished rarefaction and station KUR having additional higher frequency energy. 


\begin{tabular}{|c|c|c|c|}
\hline \multicolumn{4}{|c|}{$\begin{array}{c}\text { Table } 2 \\
\text { Explosion List, Including Onset Time and Peak Pressure at } \\
\text { Station ARI }\end{array}$} \\
\hline Number & $\begin{array}{c}\text { Date } \\
\text { (mm/dd) }\end{array}$ & $\begin{array}{l}\text { Time (UTC) } \\
\text { (hh:mm:ss) }\end{array}$ & $\begin{array}{c}\text { Peak } \\
\text { Pressure (Pa) }\end{array}$ \\
\hline 1 & $07 / 19$ & $01: 32: 01$ & 28.6 \\
\hline 2 & $07 / 19$ & 02:19:11 & 55.0 \\
\hline 3 & $07 / 19$ & 02:44:39 & 14.2 \\
\hline 4 & 07/19 & 03:04:47 & 115.9 \\
\hline 5 & $07 / 19$ & 05:11:45 & 104.9 \\
\hline 6 & 07/19 & 10:50:48 & 135.1 \\
\hline 7 & $07 / 20$ & 03:11:56 & 44.2 \\
\hline 8 & $07 / 20$ & 07:12:10 & 409.1 \\
\hline 9 & $07 / 20$ & 21:15:06 & 215.0 \\
\hline 10 & $07 / 20$ & $22: 33: 23$ & 248.6 \\
\hline 11 & $07 / 20$ & 23:06:58 & 357.1 \\
\hline 12 & $07 / 20$ & $23: 21: 50$ & 449.5 \\
\hline 13 & $07 / 21$ & 00:55:56 & 28.6 \\
\hline 14 & $07 / 21$ & 02:22:25 & 103.8 \\
\hline 15 & $07 / 21$ & 05:04:54 & 180.2 \\
\hline 16 & $07 / 21$ & 07:59:45 & 57.3 \\
\hline 17 & $07 / 21$ & 11:02:13 & 426.2 \\
\hline 18 & $07 / 21$ & 11:20:09 & 72.4 \\
\hline 19 & $07 / 22$ & 07:36:06 & 153.2 \\
\hline 20 & $07 / 22$ & 11:20:19 & 145.1 \\
\hline 21 & $07 / 22$ & $12: 35: 23$ & 13.1 \\
\hline 22 & $07 / 22$ & 12:59:33 & 173.9 \\
\hline 23 & $07 / 22$ & 14:34:00 & 172.1 \\
\hline 24 & $07 / 23$ & 08:00:45 & 30.1 \\
\hline 25 & $07 / 23$ & 20:08:40 & 16.5 \\
\hline 26 & $07 / 23$ & 21:51:41 & 75.1 \\
\hline 27 & $07 / 23$ & 23:11:29 & 182.7 \\
\hline 28 & $07 / 24$ & 05:02:31 & 13.7 \\
\hline 29 & $07 / 25$ & 01:09:36 & 48.5 \\
\hline 30 & $07 / 25$ & 14:06:55 & 16.2 \\
\hline 31 & $07 / 25$ & 15:07:50 & 16.3 \\
\hline 32 & $07 / 25$ & 17:55:06 & 93.6 \\
\hline 33 & $07 / 26$ & 00:10:05 & 33.0 \\
\hline 34 & $07 / 26$ & 04:41:07 & 23.3 \\
\hline
\end{tabular}

Figure $8 \mathrm{a}$ shows the power spectral density using a multitaper method for the waveforms in Figure 7, whereas Figure 8b shows the difference in spectral level for each station using station ARI as a reference. The amplitudes have been corrected for $1 / r$ attenuation to $1 \mathrm{~km}$. The difference spectra were calculated on a $\log$ scale between 0.1 and $20 \mathrm{~Hz}$ and were smoothed to emphasize the overall trends in spectral levels. ARI is used as the reference station because it appears to have the least amount of propagation effects related to topography (Kim and Lees, 2014). HAR and SVO are reduced 10-15 dB down relative to the reference below $1 \mathrm{~Hz}$ and reduced more than $20 \mathrm{~dB}$ above $5 \mathrm{~Hz}$. Surprisingly, KUR is $0-10 \mathrm{~dB}$ down below $1 \mathrm{~Hz}$ and shows additional energy above $1 \mathrm{~Hz}$. Station KOM has lower spectral levels of about $5 \mathrm{~dB}$ below $1 \mathrm{~Hz}$ and $5-15 \mathrm{~dB}$ above $1 \mathrm{~Hz}$ (Fig. 8b). It is notable that weaker or no audible sound was heard at stations HAR and SVO, contrasting with the loud "booms" and "pops" observed at other stations during explosions. This is consistent with the spectra in Figure 8.

The significant topography around Sakurajima is the likely cause of the waveform variability between stations (e.g., Kim and Lees, 2014). Figure 9a shows a 3D perspective map of Sakurajima and the infrasound deployment, whereas Figure 9b shows the station-vent profiles. Stations ARI, KOM, and KUR have relatively unobstructed line-of-sight views of the active vent, whereas stations HAR and SVO are blocked by the volcano summit. Because line-of-sight is obscured to HAR and SVO, sound must diffract around the summit to reach these stations. This explains the diminished high frequencies (Fig. 8) and generally lower amplitudes (Fig. 7) at these stations. Longer wavelength, lower frequency sound will diffract more effectively around the topography and will thus experience lower attenuation. Any topographic barrier greater than the wavelength (e.g., $340 \mathrm{~m}$ for a $1 \mathrm{~Hz}$ sound wave) will likely cause significant diffraction (Pierce, 1981), as well as longer propagation paths and travel times to the sites. Winds are unlikely to be responsible for the variability observed at Sakurajima due to the relatively close station-vent distances and low wind speeds (McKee et al., 2014).

The topographic obstruction to the west of the active vent (Figs. 1 and 9) may also act as a significant sound reflector. Yokoo et al. (2014) demonstrate that reflections resulting in multipathing contribute significantly to the infrasound coda following large explosions. Station KUR, positioned almost directly east, has additional high-frequency energy that may result from reflections off the topography (Figs. 8 and 9). Manuscripts in this Focus Section by Kim and Lees (2014), McKee et al. (2014), and Yokoo et al. (2014) discuss acoustic propagation and topographic effects at Sakurajima in more detail. They complement recent studies that have noted the significant effect of topography and diffraction on acoustic propagation from volcanoes (e.g., Kim and Lees, 2011; Lacanna and Ripepe, 2012), including a study by Lacanna et al. (2014) on regional (tens of kilometers) infrasound propagation from Sakurajima in which wind is shown to play an important role.

In addition to transient explosions, Sakurajima also produces many examples of continuous, lower amplitude infrasonic tremor. Figure 10 shows $1 \mathrm{~h}$ of data from station ARI containing two large explosions and multiple tremor episodes. The data is filtered between 0.3 and $10 \mathrm{~Hz}$ and the amplitude limit is $\pm 5 \mathrm{~Pa}$ to emphasize the lower amplitude tremor compared to the highamplitude explosion pluses. As is common for other explosions, $2-5$ min of $\sim 0.3-3 \mathrm{~Hz}$ infrasonic tremor follows the highamplitude explosions at 11:02 and 11:20 UTC. Multiple other tremor episodes during this period do not follow explosions. Some spectral banding is apparent in the tremor at $\sim 1.5$ and $3 \mathrm{~Hz}$ and may reflect either a source process or reflections/ reverberations from crater topography as has been noted for 

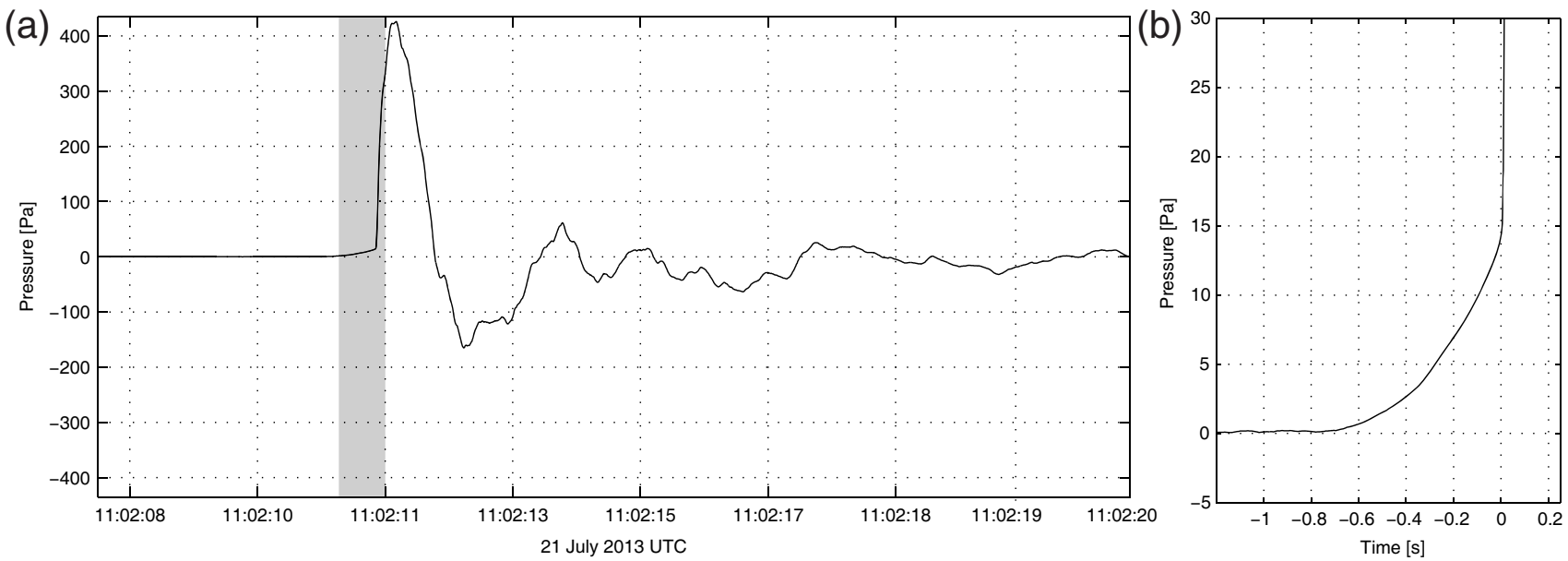

A Figure 5. Example explosion at station ARI. (a) Fifteen seconds of unfiltered data from station ARI, showing the high-amplitude explosion and (b) the slow precursory rise prior to the explosion. Time period in (b) is highlighted as the gray area in (a).

other volcanoes (e.g., Fee et al., 2010; Goto and Johnson, 2011). Infrasonic tremor also persists for longer periods, including for numerous consecutive hours on 21 July (Fig. 3), suggestive of extended open-vent periods. Infrasonic tremor at Sakurajima is usually coincident with sustained low-level ash emissions typically rising $<1 \mathrm{~km}$ above the vent. The tremor may also reflect jetting process and resemble a low frequency form of jet noise (e.g., Matoza, Fee, et al., 2009). As with explosion

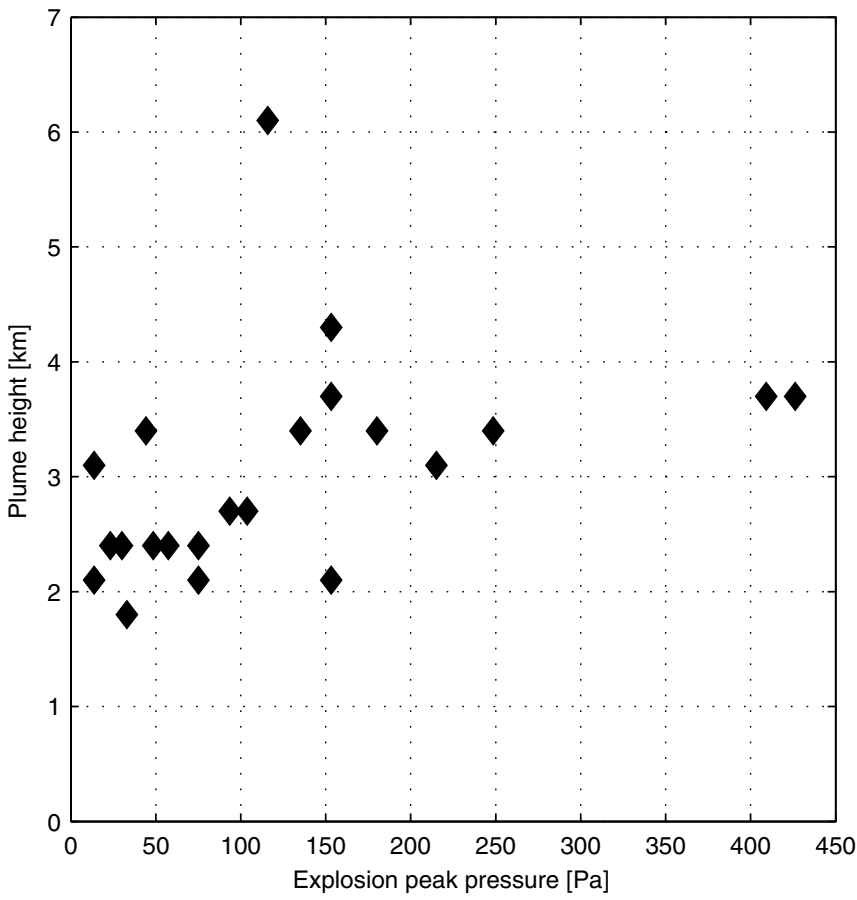

A Figure 6. Plume height versus peak pressure for the 34 detected high-amplitude explosions. No strong correlation exists between the two parameters. Plume heights are from the Tokyo VAAC, and peak pressures are from station ARI.

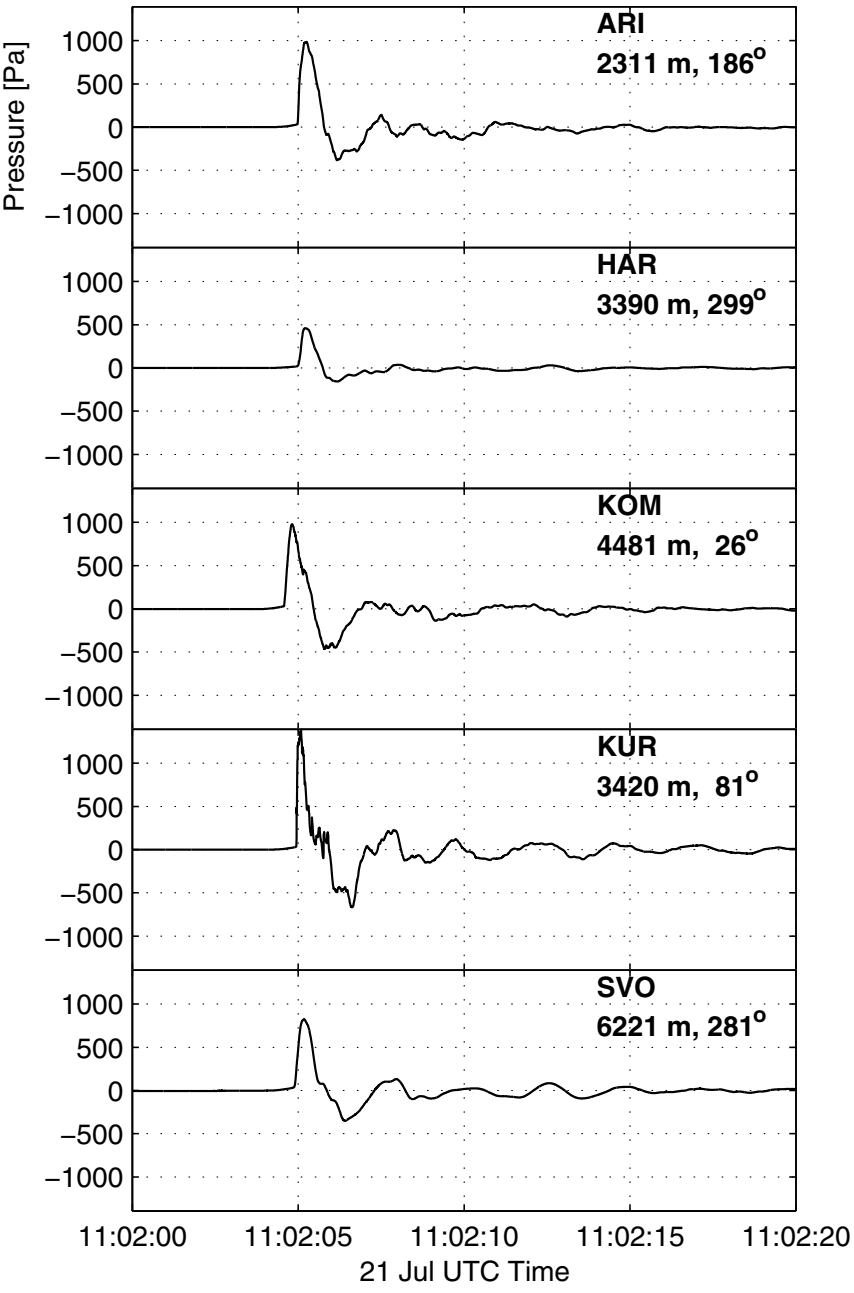

$\Delta$ Figure 7. Reduced pressure for all five network stations for a high-amplitude explosion. Significant amplitude and waveform variability exists, likely related to topography. Station name, slant distance to the vent, and azimuth are also listed. Pressure is reduced to $1 \mathrm{~km}$ for all stations, and travel time is removed assuming line-of-sight propagation. 

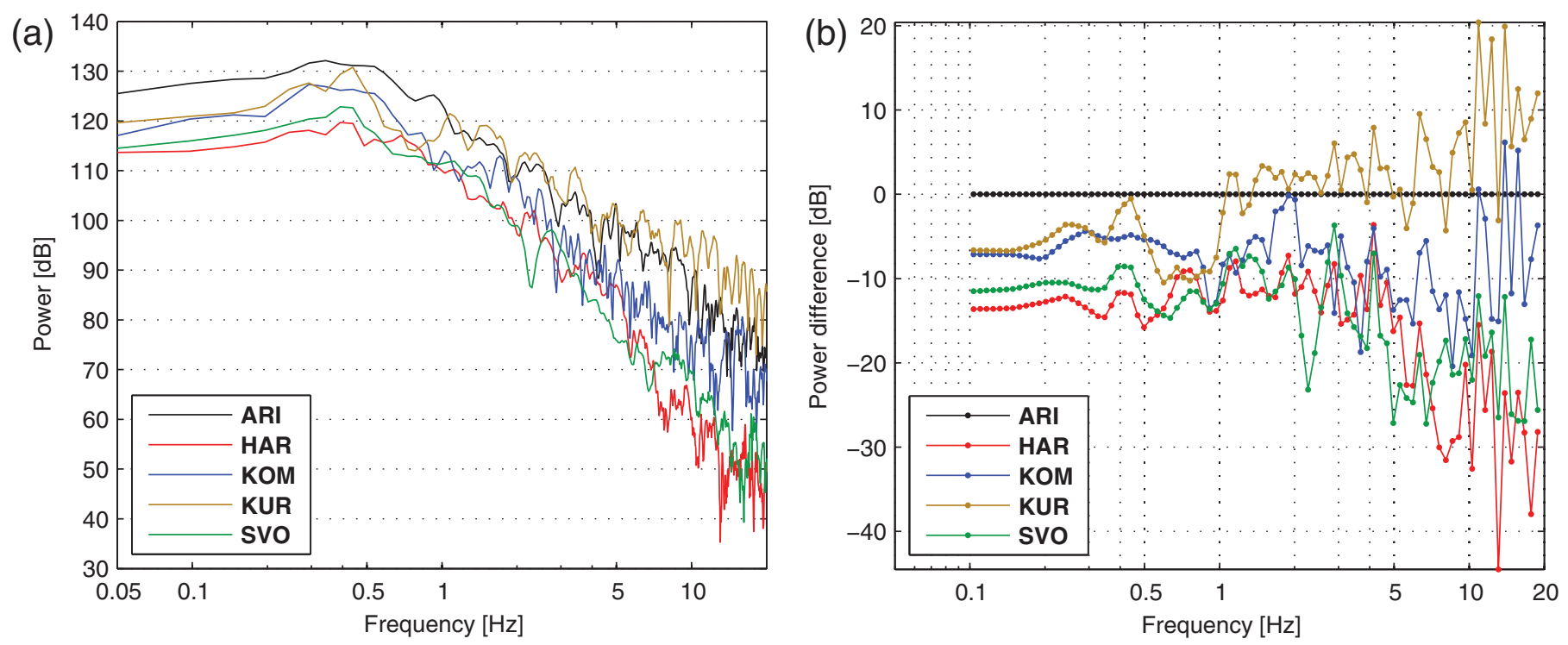

A Figure 8. Spectral comparison for explosion in Figure 7. (a) Power spectral density for reduced pressure waveforms. Amplitude is in decibel relative to $20 \times 10^{-6} \mathrm{~Pa}^{2} / \mathrm{Hz}$. (b) Difference in spectral levels using station ARI as a reference. All stations show a general reduction below $1 \mathrm{~Hz}$. Above $1 \mathrm{~Hz}$, KUR has additional energy whereas stations HAR and SVO have significant reductions.
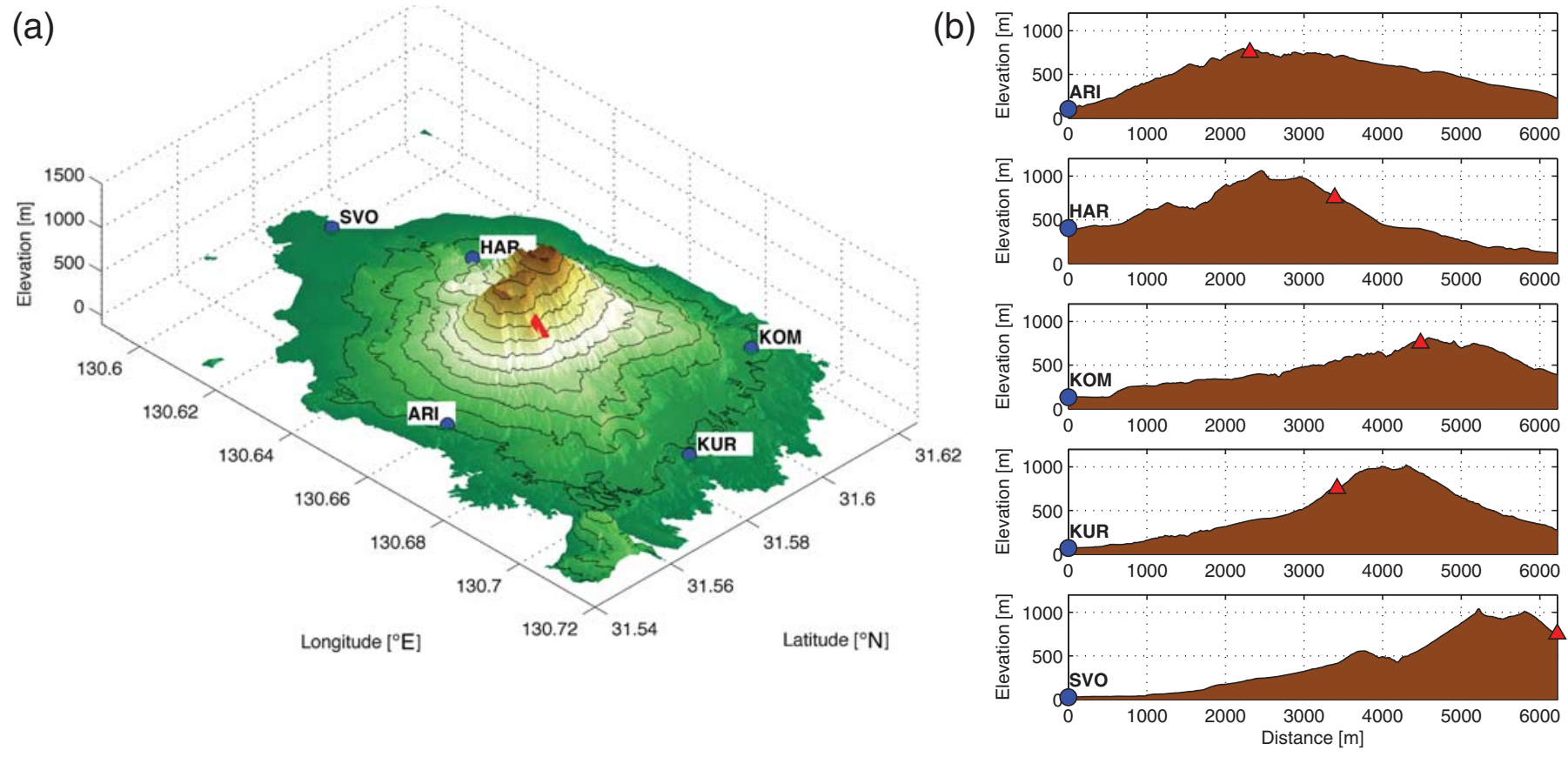

A Figure 9. (a) Three-dimensional perspective map of Sakurajima and the infrasound network deployment. (b) Station-vent profiles for each of the network stations. Stations HAR and SVO have significant topographical obstacles between the station and vent. Red triangle indicates the active vent with Showa crater.

waveforms, propagation effects cause station-dependent variability that is regularly observable in tremor waveforms.

\section{CONCLUSIONS}

In July 2013, a unique infrasound dataset was collected at Sakurajima Volcano, Japan, as part of a workshop focused on volcano acoustics. This dataset features high-quality infrasound recorded on both infrasound arrays and a network. Sakurajima produced extensive and varied infrasound during the deployment, including over 34 high-amplitude explosions, infrasonic tremor, and numerous other smaller events. Vent sealing, indicated by a lack of infrasound, often precedes the large vulcanian explosions, and lower amplitude tremor often 

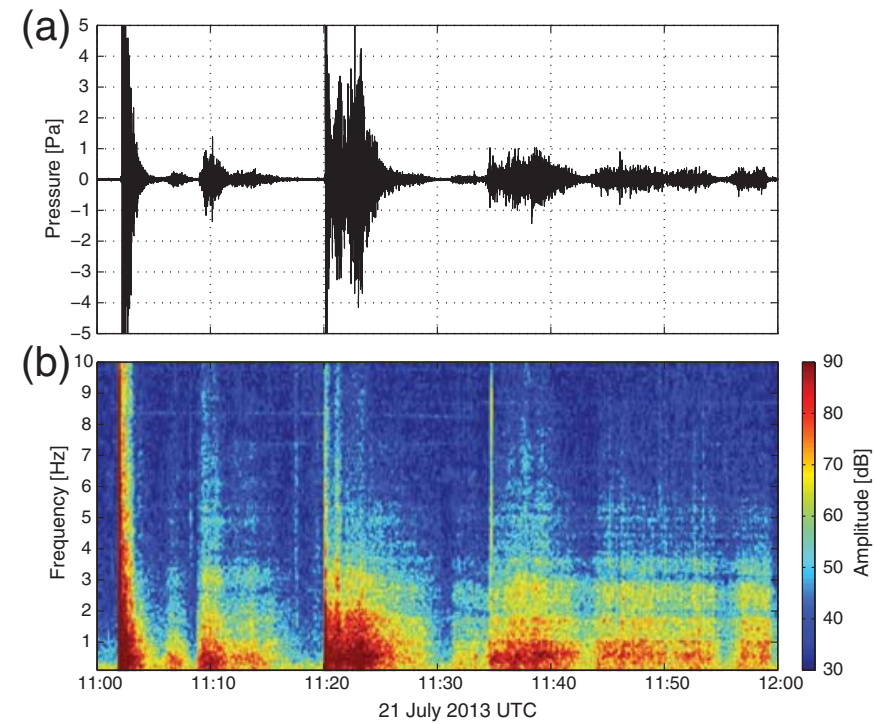

A Figure 10. Sakurajima infrasonic tremor on 21 July 1100-1200 UTC. (a) Waveforms and (b) spectrogram with two explosions at 1102 and 1120 and subsequent tremor. A third sustained tremor episode begins around 1135 but is not preceded by an explosion.

follows. Ash plumes resulting from the explosions range in height between $\sim 1.5$ and $6 \mathrm{~km}$.a.s.l. and show no strong correlation with acoustic pressure. Sakurajima also produces sustained periods (hours) of open-vent activity and infrasonic tremor associated with lower altitude ash-rich plumes. Explosion waveforms vary significantly between explosions. Some explosions have simple bipolar compressions/rarefactions, whereas others begin with multiple compression and reduced rarefactions, indicating complicated fragmentation of the viscous lava plug.

The Sakurajima infrasound dataset contains significant station-dependent variability. Stations for which propagation paths are obstructed by significant topographic obstacles show reduced amplitudes, particularly at high frequency. Reflections off nearby topography may also complicate the waveforms recorded across the network. This suggests caution must be taken in the analysis of infrasound waveforms. Various acoustic wave propagation effects must be addressed before inferring and inverting for source processes. Sampling of the full wavefield, both azimuthally and radially, is thus necessary in these types of situations. Quantification of signal amplitude, in the form of reduced pressure, or infrasound energy should take into consideration the effects of near-vent topography, as well as more distant propagation effects. Further work is needed to address the effects of complex topography and source variability on longer range acoustic propagation. Perhaps volcanoes with less extreme topography are less affected.

The dataset introduced here is explored in greater detail within this Focus Section. The data itself are available for use by the community for teaching, training, and research. Further detailed source and propagation studies are possible with this dataset. We hope that the data and research topics contained herein will accelerate advances in the field of volcano acoustics and also help educate future researchers. $\mathbf{z}$

\section{ACKNOWLEDGMENTS}

The experiment would not have occurred without the invaluable help of Sakurajima Volcano Observatory, including site access and general assistance. The Ministry of Land, Infrastructure, Transport and Tourism provided access for the KTG site. Numerous people assisted with the field installations, including Colin Rowell, Kathleen McKee, Philippa Demonte, Brian Terbush, Robin Matoza, Elizabeth Swanson, and Yuki Abe, and the authors are grateful for their help. Mie Ichihara greatly assisted with planning and running the workshop, as did Giorgio Lacanna. Tarumizu city and Kurokami elementary school provided vital assistance and meeting space for the workshop as well. This work was made possible with financial support from National Science Foundation EAR Grant Numbers 1113294 and 1151662 and the Geophysical Institute.

\section{REFERENCES}

Arrowsmith, S. J., J. B. Johnson, D. P. Drob, and M. A. H. Hedlin (2010). The Seismoacoustic wavefield: A new paradigm in studying geophysical phenomena, Rev. Geophys. 48, doi: 10.1029/2010RG000335.

Fee, D., and R. S. Matoza (2013). An overview of volcano infrasound: From hawaiian to plinian, local to global, J. Volcanol. Geoth. Res. 249, 123-139.

Fee, D., M. Garces, M. Patrick, B. Chouet, P. Dawson, and D. Swanson (2010). Infrasonic harmonic tremor and degassing bursts from Halema'uma'u Crater, Kilauea Volcano, Hawaii, J. Geophys. Res. 115, no. B11316.

Garces, M., M. Iguchi, K. Ishihara, M. Morrissey, Y. Sudo, and T. Tsutsui (1999). Infrasonic precursors to a vulcanian eruption at Sakurajima volcano, Japan, Geophys. Res. Lett. 26, 2537-2540.

Goto, A., and J. B. Johnson (2011). Monotonic infrasound and Helmholtz resonance at Volcan Villarrica (Chile), Geophys. Res. Lett. 38, no. 6, doi: 10.1029/2011GL046858.

Ichihara, M., M. Takeo, A. Yokoo, J. Oikawa, and T. Ohminato (2012). Monitoring volcanic activity using correlation patterns between infrasound and ground motion, Geophys. Res. Lett. 39, L04304, doi: 10.1029/2011GL050542.

Iguchi, M., and K. Ishihara (1990). Comparison of earthquakes and airshocks accompanied with explosive eruptions at Sakurajima and Sawunosejima volcanoes, Ann. Disaster Prev. Res. Inst. Kyoto Univ. 33B-1, 1-12.

Iguchi, M., T. Tameguri, Y. Ohta, S. Ueki, and S. Nakao (2013). Characteristics of volcanic activity at Sakurajima volcano's Showa crater during the period 2006 to 2011, Bull. Volcanol. Soc. Japan 58, 113-135.

Iguchi, M., H. Yakiwara, T. Tameguri, M. Hendrasto, and J.-i. Hirabayashi (2008). Mechanism of explosive eruption revealed by geophysical observations at the Sakurajima, Suwanosejima and Semeru volcanoes, J. Volcanol. Geoth. Res. 178, 1-9.

Ishihara, K. (1985). Dynamic analysis of volcanic explosion, J. Geodyn. 3, $327-349$.

Ishihara, K. (1990). Pressure sources and induced ground deformation associated with explosive eruptions at an andesitic volcano: Sakurajima volcano, Japan, in Magma Transport and Storage, M. P. Ryan (Editor), John Wily \& Sons, New York, 335-356.

Johnson, J., R. Aster, K. R. Jones, P. Kyle, and B. McIntosh (2008). Acoustic source characterization of impulsive Strombolian eruptions from the Mount Erebus lava lake, J. Volcanol. Geoth. Res. 177, 673-686. 
Johnson, J. B., and A. J. C. Miller (2014). Application of the monopole source to quantify explosive flux during vulcanian explosions at Sakurajima Volcano (Japan), Seismol. Res. Lett. 85, no. 6, doi: 10.1785/0220140058.

Johnson, J. B., and M. Ripepe (2011). Volcano infrasound: A review, J. Volcanol. Geoth. Res. 206, 61-69.

Johnson, J. B., J. Anderson, O. Marcillo, and S. Arrowsmith (2012). Probing local wind and temperature structure using infrasound from Volcan Villarrica (Chile), J. Geophys. Res. 117, D17107, doi: 10.1029/2012JD017694.

Kamo, K., K. Ishihara, and M. Tahira (1994). Infrasonic and seismic detection of explosive eruptions at Sakurajima volcano, Japan, and the Pegasas-VE early-warning system, in Volcanic Ash and Aviation Safety, U.S. Geological Survey, Seattle, Washington, U.S.A., 357-365.

Kim, K., and J. M. Lees (2011). Finite-difference time-domain modeling of transient infrasonic wavefields excited by volcanic explosions, Geophys. Res. Lett. 38, L06804, doi: 10.1029/2010gl046615.

Kim, K., and J. M. Lees (2014). Local volcano infrasound and source localization investigated by 3D simulation, Seismol. Res. Lett. 85, no. 6, doi: $10.1785 / 0220140029$.

Kim, K., J. M. Lees, and M. Ruiz (2012). Acoustic multipole source model for volcanic explosions and inversion for source parameters, Geophys. J. Int. 191, 1192-1204.

Kobayashi, T., D. Miki, T. Sasaki, M. Iguchi, T. Yamamoto, and K. Uto (2013). Geological map of Sakurajima volcano, Geol. Surv. Japan, AIST, scale of map: 1:25,000.

Lacanna, G., and M. Ripepe (2012). Influence of near-source volcano topography on the acoustic wavefield and implication for source modeling, J. Volcanol. Geoth. Res. 250, 9-18, doi: 10.1016/j.jvolgeores.2012.10.005.

Lacanna, G., M. Ichihara, M. Iwakuni, M. Takeo, M. Iguchi, and M. Ripepe (2014). Influence of atmospheric structure and topography on infrasonic wave propagation, J. Geophys. Res., doi: 10.1002/2013JB010827.

Lopez, T., D. Fee, F. Prata, and J. Dehn (2013). Characterization and interpretation of volcanic activity at Karymsky Volcano, Kamchatka, Russia, using observations of infrasound, volcanic emissions, and thermal imagery, Geochem. Geophys. Geosys. 14, 5106-5127.

Marcillo, O., J. B. Johnson, and D. Hart (2012). Implementation, characterization, and evaluation of an inexpensive low-power low-noise infrasound sensor based on a micromachined differential pressure transducer and a mechanical filter, J. Atmos. Ocean. Tech. 29, 1275-1284.

Matoza, R. S., and D. Fee (2014). Infrasonic component of volcanoseismic eruption tremor, Geophys. Res. Lett. 41, doi: 10.1002/ 2014 GL059301.

Matoza, R. S., D. Fee, M. A. Garces, J. M. Seiner, P. A. Ramon, and M. A. H. Hedlin (2009). Infrasonic jet noise from volcanic eruptions, Geophys. Res. Lett. 36, L08303, doi: 10.1029/2008GL036486.

Matoza, R. S., D. Fee, and T. Lopez (2014). Acoustic characterization of explosion complexity at Sakurajima, Karymsky, and Tungurahua Volcanoes, Seismol. Res. Lett. 85, no. 6, doi: 10.1785/0220140110.

Matoza, R. S., M. A. Garces, B. A. Chouet, L. D’Auria, M. A. H. Hedlin, C. De Groot-Hedlin, and G. P. Waite (2009). The source of infrasound associated with long-period events at Mount St. Helens, J. Geophys. Res. 114, no. B4, doi: 10.1029/2008JB006128.

Matsumoto, A., M. Nakagawa, M. A. Miyasaka, and M. Iguchi (2013). Temporal variation of the petrological features of the juvenile materials during 2006 to 2010 from Showa crater, Sakurajima volcano, Kyushu, Japan, Bull. Volcanol. Soc. Japan 58, 191-212.

McKee, K., D. Fee, C. R. Rowell, and A. Yokoo (2014). Network-based evaluation of infrasound source location at Sakurajima Volcano, Japan, Seismol. Res. Lett. 85, no. 6, doi: 10.1785/0220140119.

McNutt, S. R., G. Thompson, M. E. West, D. Fee, S. Stihler, and E. Clark (2013). Local seismic and infrasound observations of the 2009 explosive eruptions of Redoubt volcano, Alaska, J. Volcanol. Geoth. Res. 259, 63-76.

Morrissey, M. M., M. Garces, K. Ishihara, and M. Iguchi (2008). Analysis of infrasonic and seismic events related to the 1998 Vulcanian eruption at Sakurajima, J. Volcanol. Geoth. Res. 175, 315-324.

Petersen, T., S. De Angelis, G. Tytgat, and S. R. McNutt (2006). Local infrasound observations of large ash explosions at Augustine Volcano, Alaska, during January 11-28, 2006, Geophys. Res. Lett. 33, L12303, doi: 10.1029/2006GL026491.

Pierce, A. D. (1981). Acoustics: An Introduction to Its Physical Principles and Applications, McGraw-Hill, New York, New York.

Shimano, T., T. Nishimura, N. Chiga, Y. Shibasaki, M. Iguchi, D. Miki, and A. Yokoo (2013). Development of an automatic volcanic ash sampling apparatus for active volcanoes, Bull. Volcanol. 75, 1-7.

Tahira, M. (1982). A study of the infrasonic Wave in the atmosphere: (II) Infrasonic waves generated by the explosions of the volcano Sakura-jima, J. Meteorol. Soc. Japan 60, 896-907.

Tameguri, T., M. Iguchi, and K. Ishihara (2002). Mechanism of explosive eruptions from moment tensor analysis of explosion earthquakes at Sakurajima volcano, Japan, Bull. Volcanol. Soc. Japan 47, 197-215.

Uhira, K., and M. Takeo (1994). The source of explosive eruptions of Sakurajima volcano, Japan, J. Geophys. Res. 99, 17,775-17,789.

Yokoo, A., and K. Ishihara (2007). Analysis of pressure waves observed in Sakurajima eruption movies, Earth Planets Space 59, 177-181.

Yokoo, A., M. Iguchi, T. Tameguri, and K. Yamamoto (2013). Processes prior to outbursts of vulcanian eruption at Showa crater of Sakurajima volcano, Bull. Volcanol. Soc. Japan 58, 163-181.

Yokoo, A., Y. J. Suzuki, and M. Iguchi (2014). Dual infrasound sources from a vulcanian eruption of Sakurajima volcano inferred from cross-array observation, Seismol. Res. Lett. 85, no. 6, doi: $10.1785 / 0220140047$.

Yokoo, A., T. Tameguri, and M. Iguchi (2009). Swelling of a lava plug associated with a Vulcanian eruption at Sakurajima Volcano, Japan, as revealed by infrasound record: Case study of the eruption on January 2, 2007, Bull. Volcanol. 71, 619-630.

\section{David Fee \\ Wilson Infrasound Observatories Alaska Volcano Observatory Geophysical Institute University of Alaska Fairbanks Fairbanks, Alaska U.S.A. dfee@gi.alaska.edu}

Akibiko Yokoo Aso Volcanological Laboratory Institute of Geothermal Sciences Kyoto University Kumamoto, Japan Jeffrey B. Johnson Dept. of Geosciences Boise State University Boise, Idaho U.S.A.

Published Online 15 October 2014 